Research Article

\title{
Experimental Study on Noncoaxial Characteristics of Saturated Remolded Loess
}

\author{
Xuemeng Jiang, Haoshuang Niu (D), Wenpeng Huang, Xuwen Shang, and Deng Wang \\ Key Laboratory for Special Area Highway Engineering of Ministry of Education, Chang'an University, Xi'an 710064, China \\ Correspondence should be addressed to Haoshuang Niu; 2017221069@chd.edu.cn
}

Received 7 April 2020; Revised 25 June 2020; Accepted 31 July 2020; Published 24 August 2020

Academic Editor: Timo Saksala

Copyright (c) 2020 Xuemeng Jiang et al. This is an open access article distributed under the Creative Commons Attribution License, which permits unrestricted use, distribution, and reproduction in any medium, provided the original work is properly cited.

\begin{abstract}
In practical engineering, if the influence of noncoaxial stress and strain is not considered, part of soil deformation will be ignored, resulting in the structural design which is not safe enough. A series of undrained tests was performed on remolded loess specimens using a hollow cylinder apparatus to examine the coupling between principal stress magnitude and direction in these specimens. First, the elastic parameters of remolded loess were obtained, and these parameters were used as the basis for investigating the noncoaxiality of the soil body under principal stress axis rotation (PSAR). The effects of elastic strain, intermediate principal stress coefficient, and magnitude of the deviatoric stress on the noncoaxiality of remolded loess were also investigated. The results of these experiments show that remolded loess exhibits significant noncoaxial behavior during PSAR. The noncoaxiality angle of remolded loess cyclically fluctuates with increases in the principal stress angle. It was also observed that the noncoaxiality angle will be overestimated if the effects of elastic strain are overlooked. Reversals in the direction of PSAR cause dramatic changes in the noncoaxiality angle. Increases in the intermediate principal stress coefficient are accompanied by increases in the noncoaxiality angle, up to a certain degree; however, these changes do not affect the development of the noncoaxiality angle. In coupled rotational tests with a range of deviatoric stress amplitudes, it was observed that changes in the deviatoric stress amplitude will affect the development of the noncoaxiality angle; increases in the deviatoric stress amplitude cause the noncoaxiality angle versus principle stress angle plot to shift to the left gradually, thus accelerating the trends of the noncoaxiality angle. Increases in the cycle number also increase the noncoaxiality of remolded loess.
\end{abstract}

\section{Introduction}

In practical engineering, the structural load always changes in a reciprocating cycle, such as vehicle load and wave load, and the direction of large principal stress will change from the horizontal direction to vertical direction and, then, to the horizontal direction from far and near. The magnitude, direction, and frequency of stress are different, showing different engineering characteristics. The principal stress cyclic rotation test with research direction and size coupling is important for engineering safety significance. At present, the research on the stress-strain state of loess under the condition of principal stress axis rotation is still imperfect, especially in the noncoaxial effect.

In classic plasticity theory, Barré de Saint-Venant proposed the assumption of stress-strain coaxiality. However, many experiments have demonstrated that this assumption does not hold in soil bodies with complex stress states.

Roscoe et al. [1] were among the first researchers to propose the concept of noncoaxiality angle; they observed significant noncoaxiality in the early stages of direct shear tests, and the stress-strain directions approached coaxiality as the specimen began to fail.

Cai et al [2] performed principal strain axis rotation (PSAR) experiments on sandy soils under various drainage conditions. It was observed that the effects of soil compaction on the noncoaxiality angle are significant under low shear stresses, but insignificant under high shear stresses.

Nakata et al. [3, 4] performed monotonic shear tests with a fixed principal stress axis on medium dense sands prepared using two different methods. They observed that Toyoura standard sand exhibits strain softening, and this effect 
becomes increasingly pronounced with increases in the stress angle. In contrast, Aio sands exhibit strain hardening, and the noncoaxiality of these specimens was not significantly affected by initial anisotropy.

In cyclic PSAR experiments, Blanc et al. [5] observed that PSAR induces much larger changes in plastic strain than in elastic strain. They also found it is necessary to exclude the effects associated with increases in elastic strain to analyze the noncoaxiality of plastic strain increments.

During a series of PSAR experiments, Sun [6] observed significant cyclic and cumulative effects in the axial strains of the specimens during loading processes. In addition, the cyclic shear stress ratio, confining pressure, and cyclic vertical stress ratio significantly influence the development of accumulated strains.

Liu et al. [7] observed significant degrees of noncoaxiality in the stress-strain relationships of $\mathrm{K} 0$-consolidated saturated silt based on triaxial directional shear tests on these soils using a GDS triaxial apparatus.

Yang [8] performed stress-strain studies on undisturbed and remolded soft clays from Hangzhou, China. It was observed that the undisturbed and remolded soil specimens display similar noncoaxial fluctuations, but the effects of noncoaxiality were amplified by the intrinsic anisotropy of the undisturbed specimen. On this basis, they proposed a model for the plastic flow of soft clay that accounts for noncoaxiality.

Based on pure undrained PSAR experiments on soft clay specimens, Qian and Du [9] concluded that noncoaxiality is induced by anisotropies in the increase or decrease of stiffness. They also observed that noncoaxiality is enhanced by cyclic strengthening and weakened by cyclic weakening.

Through the study of saturated remolded loess [10-14], some scholars have obtained the influencing factors of shear strength of remolded loess, the mechanical characteristics, dynamic characteristics, and residual deformation laws under partial drainage conditions, the calculation model of loading rate and strain, and the deformation characteristics under cyclic load, which laid a theoretical foundation for subsequent research.

Hence, many studies have been conducted on the effects of soil anisotropy and PSAR on the soil body, using sandy soil and soft clay specimens. However, very few researchers have investigated the effects of PSAR on soil anisotropy. Furthermore, the stress-strain trends of a soil body during PSAR have not been thoroughly investigated, and the underlying mechanisms of these trends are largely unknown. In this study, a hollow cylinder apparatus (HCA) was used to study the noncoaxiality of saturated remolded loess and the factors that influence its noncoaxiality. First, the elastic parameters of remolded loess were obtained by performing coupled principal stress amplitude-PSAR tests with repeated cyclic loads on remolded loess in undrained conditions. Based on PSAR stress paths, we investigated the development of elastic strains in remolded loess. The effects of elastic strain, intermediate principal stress coefficient $(b)$, deviatoric stress amplitude $(\Delta q)$, and the number of cycles on the noncoaxiality of remolded loess were investigated, in addition to the underlying mechanisms of these effects. Finally, a noncoaxial constitutive model was constructed for saturated loess, thus providing an experimental reference for future studies about the deformation characteristics of saturated loess under PSAR.

\section{Experimental Design}

2.1. Experimental Apparatus and Specimen Preparation. An HCA in Chang'an University was used to study the stress characteristics of remolded loess. Yang et al. [15] provided a detailed description of the structure and function of HCAs. In an HCA, the axial load $W$, torque $T$, outer cell pressure $P 0$, and inner cell pressure $P$ can be controlled using magnetic field coils and a pneumatic loading unit, thus enabling the independent control of the axial stress $\sigma_{z}$, radial stress $\sigma_{r}$, circumferential stress $\sigma_{\theta}$, and shear stress $\tau_{z \theta}$. This facilitates the simulation of complex soil conditions. The structure of the HCA used in this study is shown in Figure 1.

This study was performed using remolded loess specimens, and their parameters are shown in Table 1. After the hollow cylinder specimens were prepared and loaded into the HCA, back pressure saturation was performed until the pore pressure coefficient $B$ of the soil specimen reached 0.96 (i.e., when the soil specimen reaches saturation). Isobaric consolidation was subsequently performed at an equivalent confining pressure of $150 \mathrm{kPa}$. After the sample was consolidated, the PSAR test was conducted by independently manipulating the stress parameters $p, q, b$, and $\alpha$. The definitions of these parameters are as follows:

$$
\begin{aligned}
& p=\frac{1}{3}\left(\sigma_{1}+\sigma_{2}+\sigma_{3}\right)=\frac{1}{3}\left(\sigma_{z}+\sigma_{\theta}+\sigma_{r}\right) \\
& q=\frac{\sigma_{1}-\sigma_{3}}{2}=\sqrt{\left(\frac{\sigma_{z}-\sigma_{\theta}}{2}\right)^{2}+\tau_{z \theta}^{2}} \\
& b=\frac{\sigma_{2}-\sigma_{3}}{\sigma_{1}-\sigma_{3}}=\frac{\sigma_{r}-\left(\left(\sigma_{z}+\sigma_{\theta}\right) / 2\right)+\sqrt{\left(\left(\sigma_{z}+\sigma_{\theta}\right)^{2} / 4\right)+\tau_{z \theta}^{2}}}{2 \sqrt{\left(\left(\sigma_{z}+\sigma_{\theta}\right)^{2} / 4\right)+\tau_{z \theta}^{2}}} \\
& \alpha=\frac{1}{2} \arctan \frac{2 \tau_{z \theta}}{\sigma_{z}-\sigma_{\theta}} .
\end{aligned}
$$

In these equations, $\sigma_{z}, \sigma_{r}, \sigma_{\theta}$, and $\tau_{z \theta}$ are the axial stress, radial stress, circumferential stress, and shear stress, respectively. If $p$ and $b$ are fixed, the stress components acting on a specimen must adhere to certain relationships during PSAR:

$$
\begin{aligned}
& \sigma_{z}=p-\frac{(b q-q) / 2}{3}+\frac{1}{2} q \cos (2 \alpha), \\
& \sigma_{r}=p+\frac{2((b q-q) / 2)}{3}, \\
& \sigma_{\theta}=p-\frac{((b q-q) / 2)}{3}-\frac{1}{2} q \cos (2 \alpha),
\end{aligned}
$$




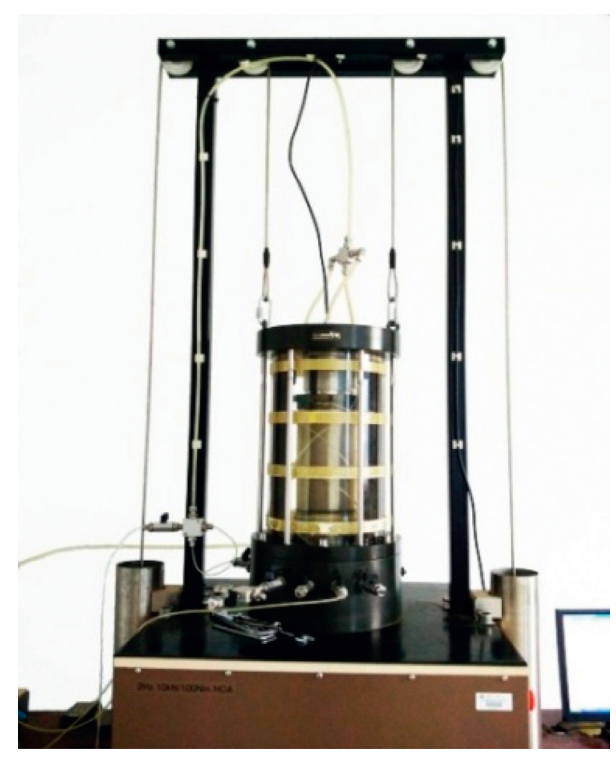

Figure 1: Hollow cylinder apparatus.

Table 1: Parameters of the soil specimen.

\begin{tabular}{lccc}
\hline Density $\left(\mathrm{g} / \mathrm{cm}^{3}\right)$ & Moisture content $(\%)$ & Internal diameter $(\mathrm{mm})$ & External diameter $(\mathrm{mm})$ \\
\hline 1.69 & 14.2 & 60 & 100 \\
\hline
\end{tabular}

$$
\tau_{z \theta}=\frac{1}{2} q \sin (2 \alpha)
$$

The trends of the stress components are therefore fully determined if $p, q, b$, and $\alpha$ are known, which are shown in Table 1.

2.2. Experimental Schemes. Coupled principal stress amplitude-PSAR tests were performed on remolded loess specimens to study the noncoaxiality of remolded loess. The experimental schemes for this purpose are listed in Table 2; I represents the test group with $b$ as the variable, and II represents the test group with $q$ as the variable.

The stress path used in this experiment is shown in Figure 2. First, the deviatoric stress $q$ was increased to a fixed point (point $B$ ); after isotropic consolidation was completed, the principal stress amplitude and principal stress angle were simultaneously varied to perform the coupled principle stress amplitude-PSAR test $(B \longrightarrow D \longrightarrow B \longrightarrow C \longrightarrow B)$. During the cyclic rotation of the principal stress axis, the magnitudes of $p$ and $b$ were maintained unchanged whereas $\alpha$ and $q$ were varied according to a constant ratio.

\subsection{Experimental Steps}

2.3.1. Sample Preparation. After the natural soil is crushed and dried, it is mixed with a certain proportion of water, and then, it is put into a grinding tool for compaction.

2.3.2. Sample Loading. Before sample installation, check whether the pipeline is connected and whether the rubber film leaks. The sample is composed of a base, permeable stone, top cover cap, and inner and outer membranes to form a closed space inside the sample. The outer cover of the pressure chamber is installed, and the water inlet valve of the pressure chamber is opened and filled with air-free water. When the pressure chamber is full of water and there is continuous water column flowing out, the water inlet valve is closed and filling water is stopped.

2.3.3. Back Pressure Saturation. The air in the pore of the sample is removed by back pressure and water without air. Due to the large size of the sample and the poor permeability of the loess, the commonly used method of back pressure saturation is used for grading saturation to compress and dissolve the original gas in the hollow cylinder, so as to achieve the saturation effect of the soil sample.

2.3.4. Consolidation Stage. Loess has creep, that is, the stress decreases gradually and the strain still increases. Because of its poor permeability, loess usually needs more than $12 \mathrm{~h}$ consolidation time.

2.3.5. Applied Stress Path. The stress path is controlled by $p$, $q, b$, and $\alpha$, and dynamic load is applied.

\section{Experimental Results and Analysis}

3.1. Elastic Parameters and Elastic-Plastic Strain. Figure 3 illustrates the axial and circumferential stress-strain curves of a remolded loess specimen obtained from cyclic loadingunloading tests on specimen Cq1. This figure shows that the 
TABle 2: Experimental schemes.

\begin{tabular}{|c|c|c|c|c|c|}
\hline Series numbering & Experiment numbering & $p(\mathrm{kPa})$ & $b$ & $q(\mathrm{kPa})$ & $\Delta \alpha\left(^{\circ}\right)$ \\
\hline \multirow{3}{*}{$\mathrm{I}$} & $\mathrm{Cb} 1$ & 250 & 0 & $40-60$ & \multirow{3}{*}{75} \\
\hline & $\mathrm{Cb} 2$ & 250 & 0.5 & $40-60$ & \\
\hline & $\mathrm{Cb} 3$ & 250 & 1 & $40-60$ & \\
\hline \multirow{3}{*}{ II } & $\mathrm{Cq} 1$ & 250 & 0 & $35-45$ & \multirow{3}{*}{75} \\
\hline & $\mathrm{Cq} 2$ & 250 & 0 & $25-45$ & \\
\hline & $\mathrm{Cq} 3$ & 250 & 0 & $20-50$ & \\
\hline
\end{tabular}

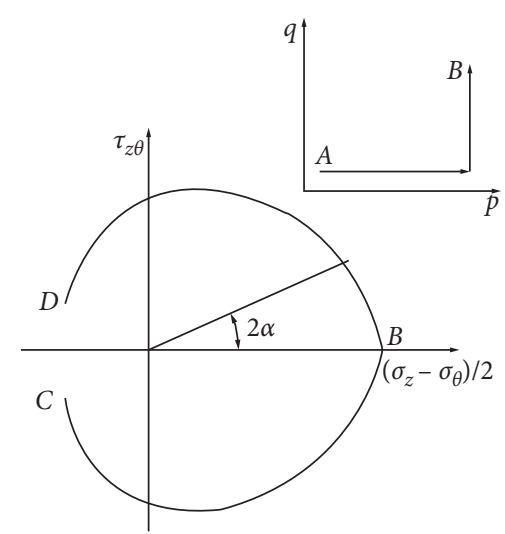

FIgURE 2: Schematic of the stress path.

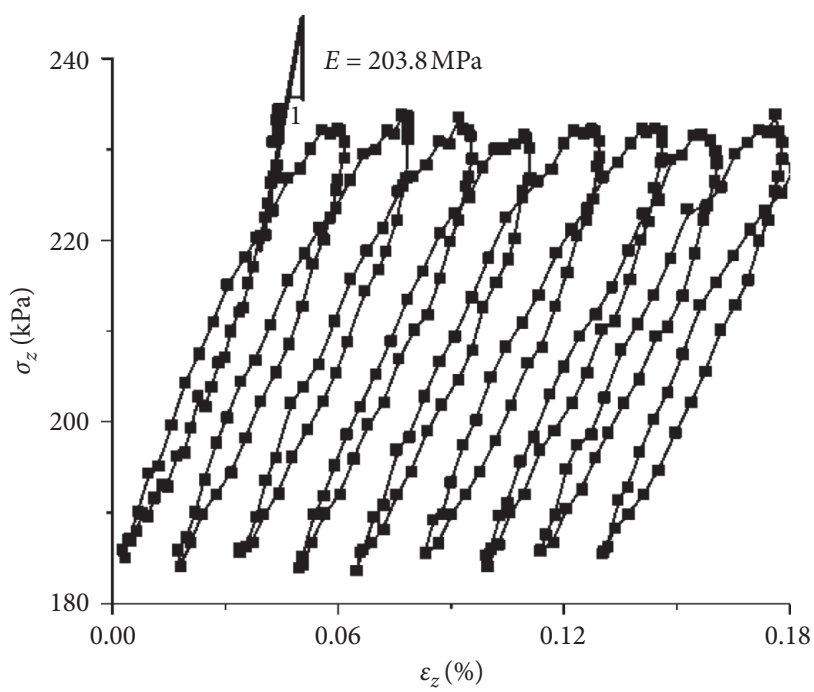

(a)

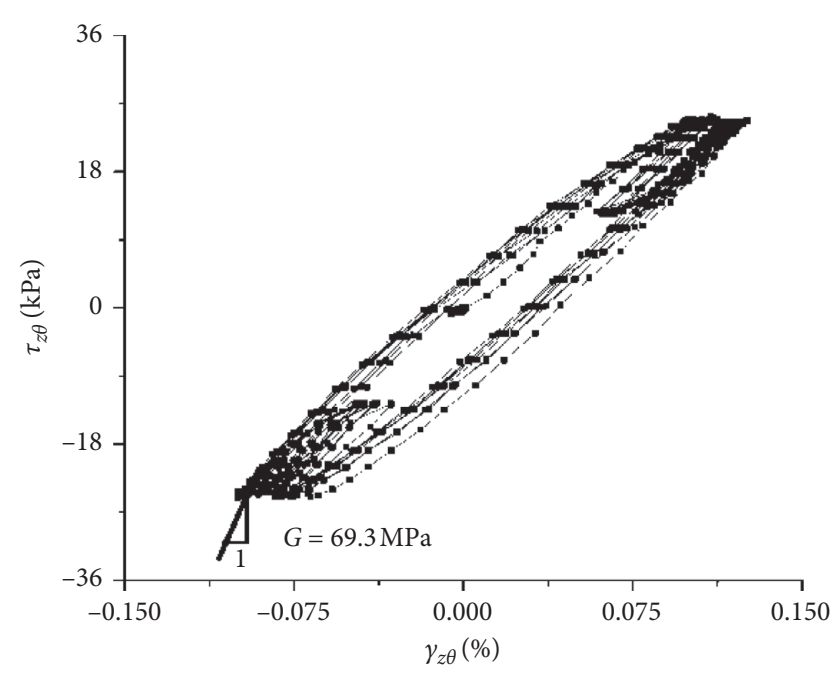

(b)

Figure 3: Stress-strain curves of Cq1: (a) axial and (b) tangential.

cyclic changes in loading are accompanied by fluctuations in strain and that there are many tilted ellipses in the stressstrain curve. Therefore, the stress-strain curves are cyclic and demonstrate a significant degree of strain hysteresis [16, 17]. It is, thus, implied that elastic strain and plastic strain are generated simultaneously during PSAR, and the degree of tilt of these strains is largely the same. If the axial stress is positive, the specimen is, then, poised in an axially compressed state, and the stress-strain curve of the specimen will be linear during the initial loading/unloading in each test. Hardin and Blandford [18] noted that the initial tangent modulus is effectively equivalent to Young's modulus of a soil body.

The initial tangent modulus of partial unloading is given by Figure 3, whereas Figure 4 illustrates the relationship between the initial tangent modulus and cycle number $N$ throughout the unloading process in specimen Cq1. In the latter, it is shown that the initial tangent modulus does not change significantly, despite the continuous development of stress and strain; it was observed that the axial and tangential tangent moduli gradually decreased from $203.8 \mathrm{MPa}$ to 186.8 $\mathrm{MPa}$ and $65.3 \mathrm{MPa}$ to $69.7 \mathrm{MPa}$, respectively. This 


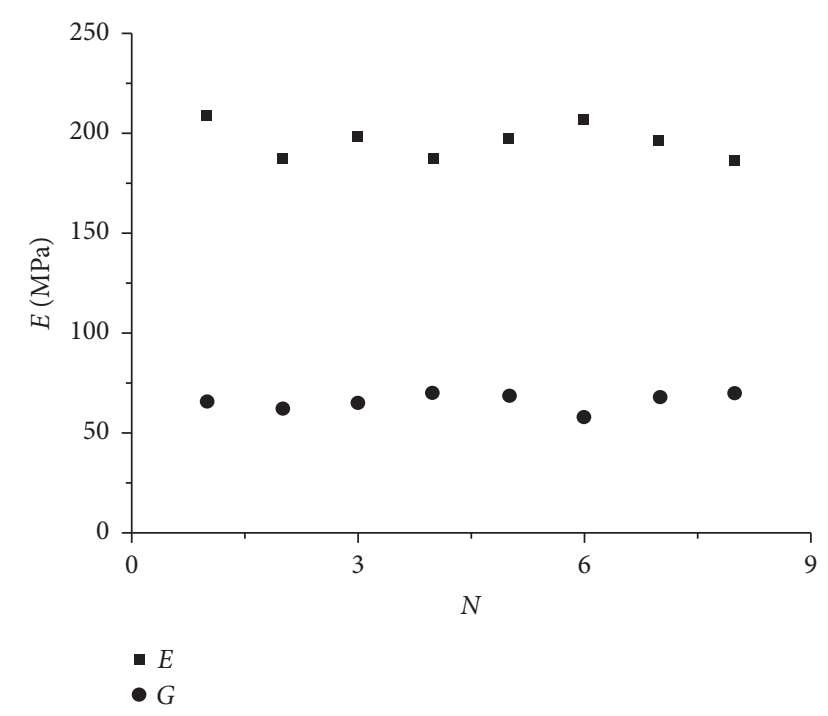

Figure 4: Changes of the initial tangent modulus in Cq1 $(N$ represents the number of cycles of cyclic load, i.e., the number of process cycles of $(B \longrightarrow D \longrightarrow B \longrightarrow C \longrightarrow B)$ ).

result indicates that Young's modulus and the tangent modulus are stable mechanical performance indicators. If plastic-elastic strain coupling is negligible, the average initial tangent moduli of each cycle indicate that axial Young's modulus and tangent modulus of the specimen were 196.2 $\mathrm{MPa}$ and $65.7 \mathrm{MPa}$, respectively. Yan et al. [19] demonstrated that the elastic parameters of a specimen in undrained conditions are isotropic at small deformations.

It was observed that $\mu=E /(2 G-1)=0.49$. As compared with silt, a greater amount of external force is required to induce each unit of elastic deformation in remolded loess. Therefore, remolded loess is stronger and more stable than silt as it is difficult to induce elastic deformations in these soils.

The differentiation of equations (2)-(5) yields the increments of each stress component in the coupled principal stress amplitude-PSAR test:

$$
\begin{gathered}
d \sigma_{z}=\frac{1}{2}\left[\frac{1-2 b}{3}+\cos (2 \alpha)\right] d q-q \sin (d 2 \alpha), \\
d \sigma_{r}=\frac{2 b-1}{3} d q \\
d \sigma_{\theta}=\frac{1}{2}\left[\frac{1-2 b}{3}-\cos (2 \alpha)\right] d q+q \sin (d 2 \alpha), \\
d \tau_{z \theta}=\frac{1}{2} \sin (2 \alpha) d q+q \cos (d 2 \alpha) .
\end{gathered}
$$

In pure cyclic PSAR tests, only the principal stress angle $\alpha \sigma$ changes during the unloading process; hence, it was set to 0 in equations (6)-(9) to obtain the increments of each stress component in this test. Based on the elastic parameters determined in the previous cyclic loading-unloading test, the elastic and plastic strains of the soil body subjected to a cyclic load may be obtained using generalized Hooke's law.
Figure 5 shows the variation of elastic and plastic strains of specimen Cq3 from the completion of its consolidation up to the end of the first cycle. Here, it is shown that the soil body simultaneously undergoes elastic and plastic deformations during the coupled principal stress amplitudePSAR test. Plastic strain amplitudes were observed to vary much more significantly than elastic strain amplitudes, with the former being approximately three times that of the latter. After the end of the first cycle, all elastic deformations were fully restored, whereas the plastic deformations were not fully restored. In Figure 5, it is also shown that the plastic strain peak clearly lags behind the elastic strain peak, which indicates that the initiation of plastic strain lags behind changes in strain. Yan et al. [19] obtained similar results in pure PSAR tests with continuous and cyclic rotation in undrained conditions.

The plastic strain paths indirectly reflect on the trends of the yield surface. As the cyclic stiffness of the soil body changes, the plastic strain paths exhibit various trajectory envelopes in the deviatoric strain plane, as shown in Figure 6. In Figure 6(a), it is shown that, when $\Delta q=10 \mathrm{kPa}$, the plastic strain paths in the deviatoric plane gradually shrink and the positions of the paths do not change significantly. Therefore, the shear stiffness of the soil body becomes stronger, and the changes in deviatoric stiffness are not significant. When $\Delta q=30 \mathrm{kPa}$, the rotation of the principal stress axis leads to shrinkage of the plastic strain paths and a lateral shift in path position, as shown in Figure 6(b). This indicates that the shear stiffness and deviatoric stiffness of the soil body both increase, which is consistent with strain hardening. Hence, the amplitude of the deviatoric stress will influence the development of soil body stiffness with increases in the cycle number.

3.2. Definition of the Noncoaxiality Angle. Figure 7 is a schematic of the features of noncoaxiality. In this figure, $\alpha$ is the stress direction angle, $\alpha_{d \sigma}$ is the stress increment direction angle, and $\beta^{p}$ is the noncoaxiality angle. The noncoaxiality angle is defined as

$$
\beta^{p}=\alpha_{d \varepsilon}^{p}-\alpha
$$

where

$$
\alpha_{d \varepsilon}^{p}=\frac{1}{2} \arctan \frac{d \gamma_{z \theta}^{p}}{d \varepsilon_{z}^{p}-d \varepsilon_{\theta}^{p}}
$$

In these equations, $d \varepsilon_{z}^{p}, d \varepsilon_{\theta}^{p}$, and $d \gamma_{z \theta}^{p}$ are the increments of the axial, circumferential, and torsional plastic strain increment, respectively.

The effects of elastic strain were generally overlooked in previous studies. Here, the noncoaxiality angle is defined as the angle between the strain increment direction and the principal stress direction:

$$
\beta^{\mathrm{tol}}=\alpha_{d \varepsilon}-\alpha,
$$

where 


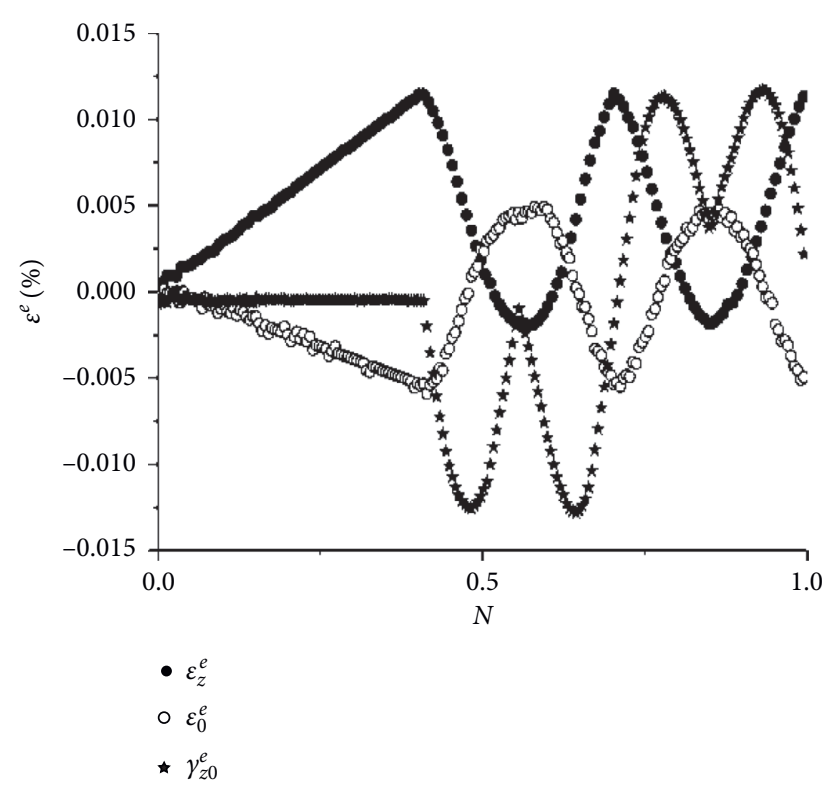

(a)

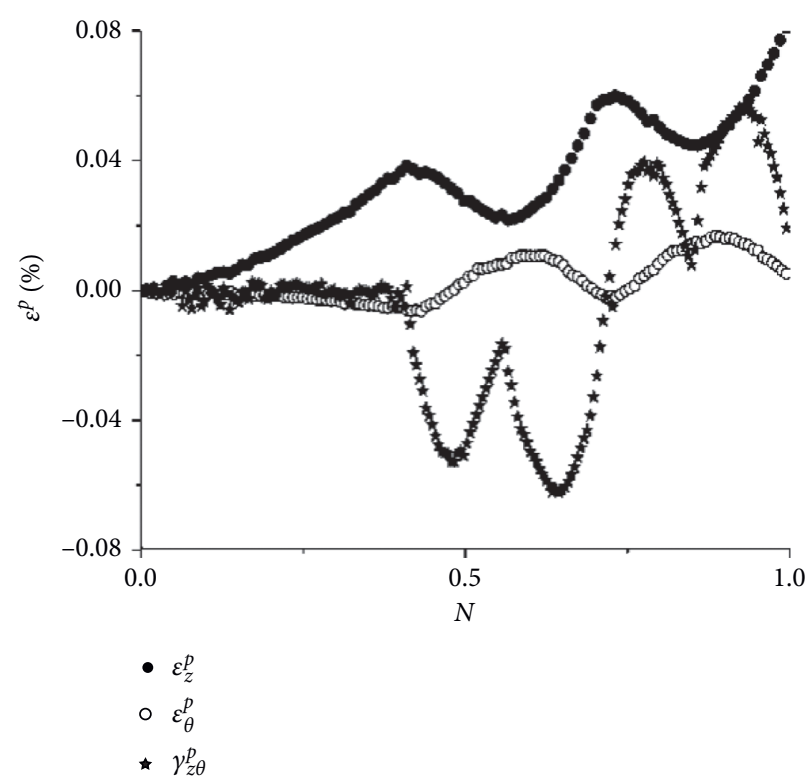

(b)

Figure 5: Elastic and plastic strains of $\mathrm{Cq} 3$ in the first cycle: (a) elastic strains and (b) plastic strains.

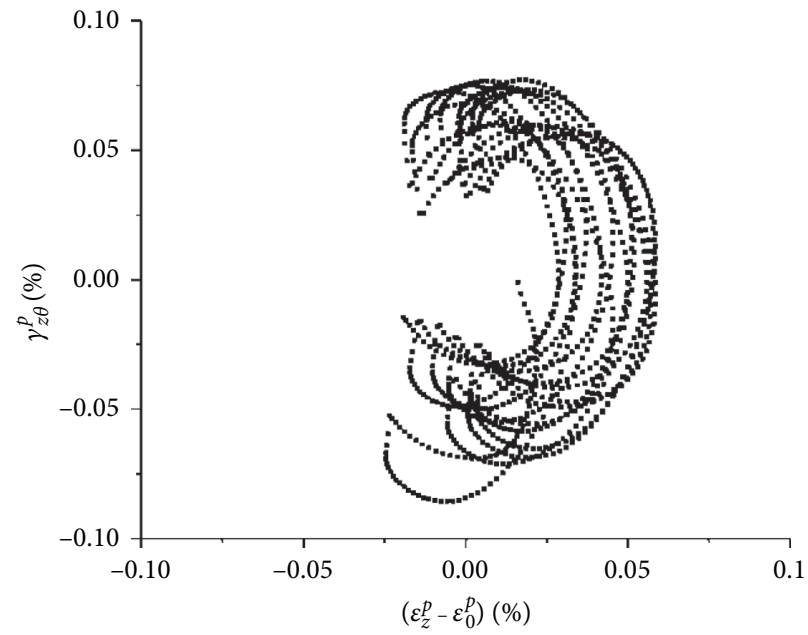

(a)

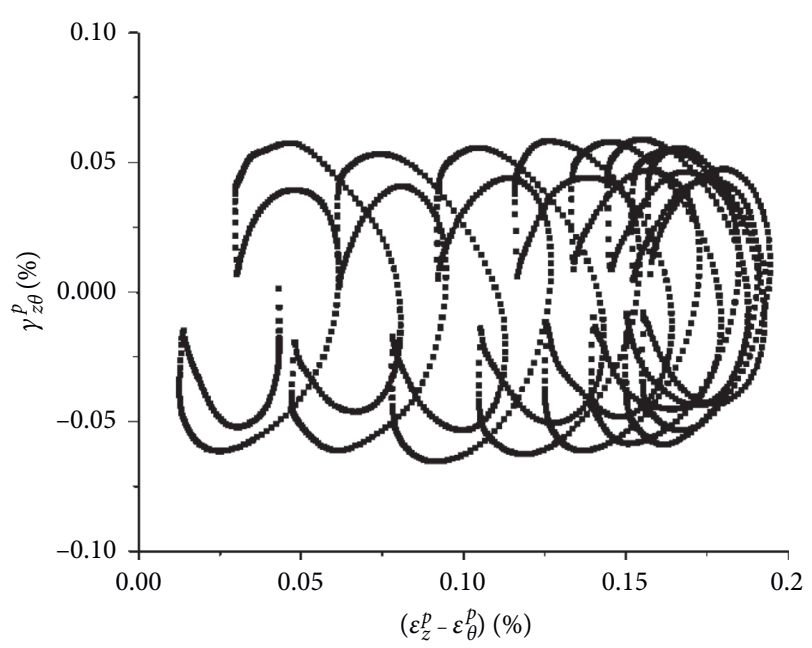

(b)

Figure 6: Trends of the plastic strain paths: (a) Cq1 and (b) Cq3.

$$
\alpha_{d \varepsilon}=\frac{1}{2} \arctan \frac{d \gamma_{z \theta}}{d \varepsilon_{z}-d \varepsilon_{\theta}} .
$$

In these equations, $d \varepsilon_{z}, d \varepsilon_{\theta}$, and $d \gamma_{z \theta}$ are the total increments of the axial, circumferential, and torsional strain increment, respectively.

To examine the effects of elastic strain on the noncoaxiality of remolded loess, the changes in the $\beta^{p}$ and $\beta^{\text {tol }}$ of Cq1 over $\alpha=\left[-75^{\circ}, 75^{\circ}\right]$ in the first cycle are shown in Figure 8. It is shown that the fluctuations of $\beta^{p}$ and $\beta^{\text {tol }}$ are very similar, and the differences between their values are minimal during the initial loading stage. Over the entirety of the loading process, $\beta^{p}$ ranges between $\left[29.03^{\circ}, 47.92^{\circ}\right.$ ] whereas $\beta^{\text {tol }}$ ranges between $\left[32.42^{\circ}, 48.24^{\circ}\right]$. In one cycle, the trend of $\beta^{p}$ is less than that of $\beta^{\text {tol }}$. In other words, the noncoaxiality of the soil body would be overestimated if the effects of elastic strain are overlooked. This is because the total strain increment also contains elastic strain increments, and the direction of the elastic strain increment is the same as that of the stress increment. Based on Figure 6, it may be inferred that the existence of elastic strain will increase the noncoaxiality angle. Therefore, the effects of elastic strain should be accounted for in studies on the noncoaxiality of plastic strains in soil bodies [5]. Notably, the effects of elastic strain in coupled conditions on the maxima of the noncoaxiality angle of remolded loess are not very large, as these effects mainly affect the minima of the noncoaxiality angle. Based on pure PSAR experiments on Hangzhou soft clay, 


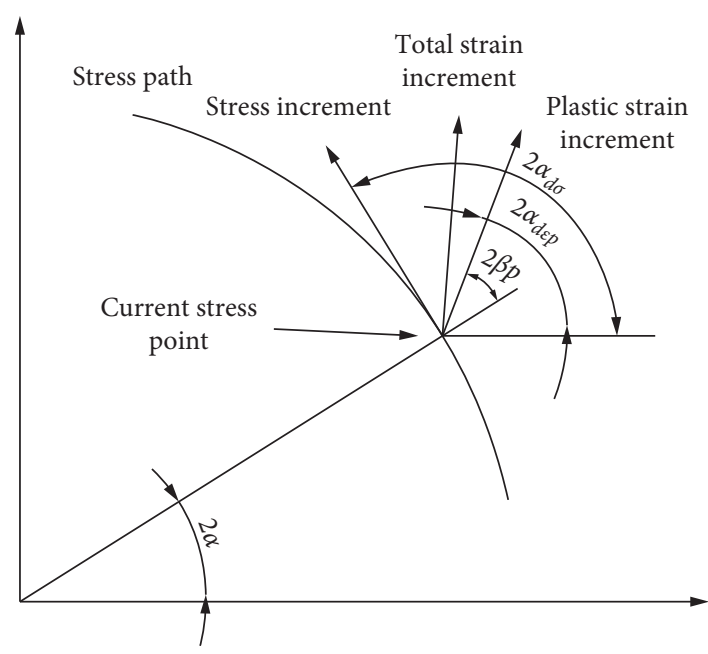

Figure 7: Schematic of the features of noncoaxiality.

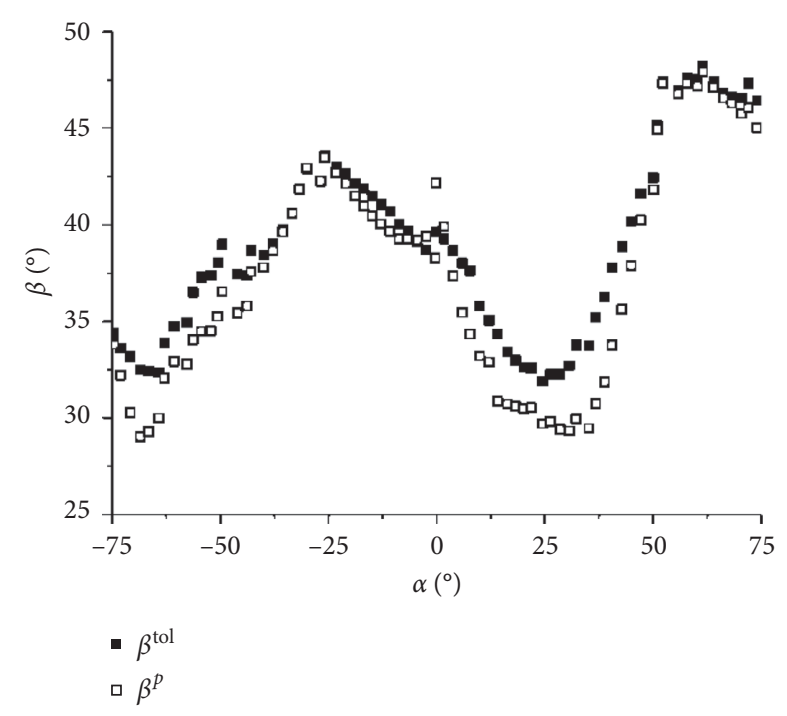

FIGURE 8: Variations of $\beta^{p}$ and $\beta^{\text {tol }}$ with changes in $\alpha$.

Yang observed that the maxima of $\beta^{\text {tol }}$ are greater than those of $\beta^{p}$. It is, thus, shown that the effects of elastic strain on noncoaxiality are different in loess than in soft clay.

When the noncoaxiality of remolded loess is examined under cyclic loads, positive and negative rotational states must coexist in the principal stress axis during each loading cycle. Figure 9 shows a plot of the noncoaxiality angle versus the two-way rotations of the principal stress axis during the first cycle of specimen Cq1. It is shown that the noncoaxial angle changes dramatically when the direction of PSAR is reversed in the range of $35^{\circ}-75^{\circ}$. Based on Figure 6 , it may be inferred that the direction of the plastic strain increment is also reversed at this point. Hence, the direction of the plastic strain increment is significantly influenced by the direction of stress increment. Pradel et al. [20] observed a similar pattern in their stress experiments on sandy soil (a small increment was added along each of the various stress directions) as they observed that the direction of strain increment changes in tow with the direction of stress increment. Figure 9 also shows that the absolute values of the noncoaxiality angle $\beta^{p}$ exhibit the same fluctuations during the two-way rotation of the principal stress axis, and the variations always occur within $\left[25^{\circ}, 47^{\circ}\right]$. Hence, the noncoaxiality of remolded loess is consistent throughout the processes of two-way PSAR. Accordingly, we focused our attention on the noncoaxiality of remolded loess during positive PSAR.

3.3. Noncoaxiality of Remolded Loess. Figure 10 shows the variation of $\beta^{p}$ in the range $\alpha=\left[-75^{\circ}, 75^{\circ}\right]$ under repeated cyclic loads with the same stress loading period, but with different intermediate principal stress coefficients $(b)$, in specimens $\mathrm{Cb} 1, \mathrm{Cb} 2$, and $\mathrm{Cb} 3$. It is shown that the three $\beta^{p}$ versus $\alpha$ plots gradually become higher during coupled rotation. The fluctuations of these plots are identical, and two peaks appear in each cycle. Hence, the value of $b$ does not affect the fluctuations of the noncoaxiality angle in remolded loess. At the beginning of each cycle, the total strain is relatively small during the initial loading. Hence, elastic strain accounts for a larger proportion of the total strain in this stage. As the elastic strain direction is the same as the principal stress direction, the noncoaxiality angle is generally small in this stage. The proportion of plastic strain in the total strain increases with further loading, thus increasing $\beta^{p}$. Figure 10 shows that larger $b$ values lead to larger $\beta^{p}$ for the same $\alpha$. A comparison between the plots in Figure 10 shows that the peak differential of the noncoaxiality angle is $6.1^{\circ}$ when $b=0,5.51^{\circ}$ when $b=0.5$, and $7.9^{\circ}$ when $b=1$. It is, thus, shown that $b$ only affects the amplitude of $\beta^{p}$ without significantly affecting its development in coupled conditions. In the experimental study by Yang et al. on soft clay samples, higher values of $b$ were observed to lead to lower values of $\beta^{p}$ at the same $\alpha$, and the effects of $b$ on $\beta^{p}$ were not especially significant. Tong et al. [20] also obtained similar results from pure PSAR tests on sandy soils with different values of $b$. The findings of these studies are not consistent with the results obtained from remolded loess specimens in this study.

Figure 11 shows the variation of $\beta^{p}$ in the range $\alpha=\left[-75^{\circ}, 75^{\circ}\right]$ under repeated cyclic loads with the same stress loading period but different deviatoric stress amplitudes $(\Delta q)$. It is shown that significant noncoaxiality is present in remolded loess during repeated cyclic loading, and the fluctuations of $\beta^{p}$ with $\alpha$ are different in each range of $\alpha$. The noncoaxiality angle generally takes smaller values when $\alpha$ is between $\left[-75^{\circ},-45^{\circ}\right]$ and $\left[0^{\circ}, 45^{\circ}\right]$. In these ranges, the rotation of the principal stress axis initially leads to decreases in $\beta^{p}$, until $\beta^{p}$ reaches its minima around $\alpha=-50^{\circ}$ and $\alpha=-25^{\circ} ; \beta^{p}$ then, increases with further increases in $\alpha . \beta^{p}$ takes larger values when $\alpha$ is between $\left[-45^{\circ}, 0^{\circ}\right]$ and $\left[45^{\circ}, 75^{\circ}\right]$. In these ranges, $\beta^{p}$ initially increases with the increase in $\alpha$, until it reaches its maxima around $\alpha=-25^{\circ}$ and $\alpha=50^{\circ} ; \beta^{p}$ then, decreases with further increases in $\alpha$. These "segmented" changes in $\beta^{p}$ with $\alpha$ were also observed in a series of tests conducted by $\mathrm{Du}$ et al. on traffic-induced loads in undisturbed saturated soft clays, where the amplitude and direction of the principle stress axis were also varied in a coupled manner [21, 22]. The maxima and minima of the 


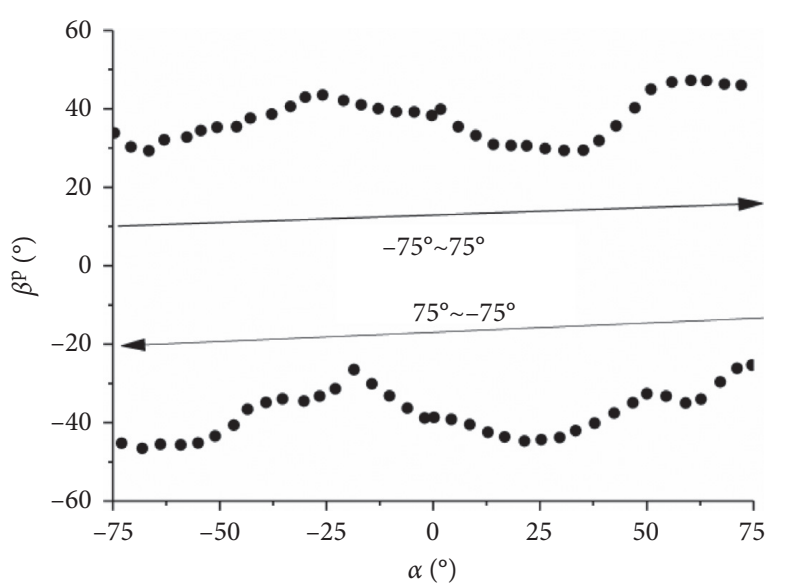

FIgURE 9: Variations of the noncoaxiality angle with different directions of rotation by the principal stress axis.

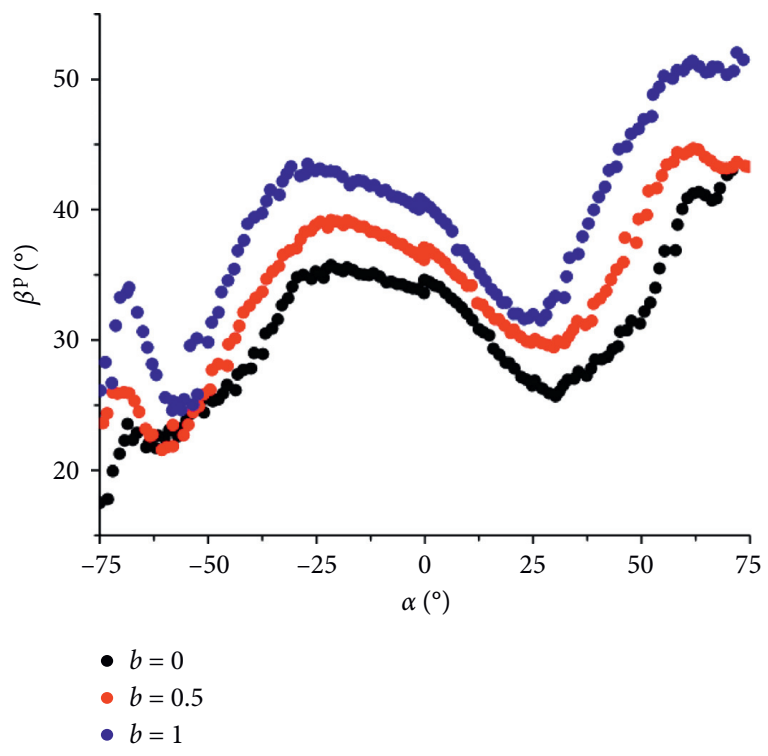

FIgURE 10: Noncoaxiality angle $\beta^{p}$ versus $\alpha$ with different values of $b$.

noncoaxiality angle plots always differ by approximately $25^{\circ}$ in each cycle. Hence, the fluctuations of $\beta^{p}$ are not significantly affected by the amplitude of the deviatoric stress, as these fluctuations are generally the same at each value of $\Delta q$.

Figure 11 also shows that all three $\beta^{p}$ versus $\alpha$ curves are very similar within $\alpha=\left[-75^{\circ}, 0^{\circ}\right]$. In this range of $\alpha$, the three curves are very similar at small values of $\alpha$, but begin to diverge around $\alpha=25^{\circ} ; \beta^{p}$ is generally larger beyond this point than in the previous range of $\alpha$ values, and this change is more pronounced at larger $\Delta q$ values. The peak differential of $\beta^{p}$ is $5.01^{\circ}$ when $\Delta q=10 \mathrm{kPa}$, but this increases to $16.39^{\circ}$ and $23.98^{\circ}$ when $\Delta q=20 \mathrm{kPa}$ and $\Delta q=30 \mathrm{kPa}$, respectively. It is, thus, shown that the amplitude of the deviatoric stress will affect the trends and amplitude of the noncoaxiality angle in coupled conditions.

Figure 12 illustrates several $\beta^{p}$ versus $\alpha$ plots with different cycle numbers $(N)$. This figure illustrates how $N$ affects the noncoaxiality angle using specimen $\mathrm{Cq} 2$ as an example.

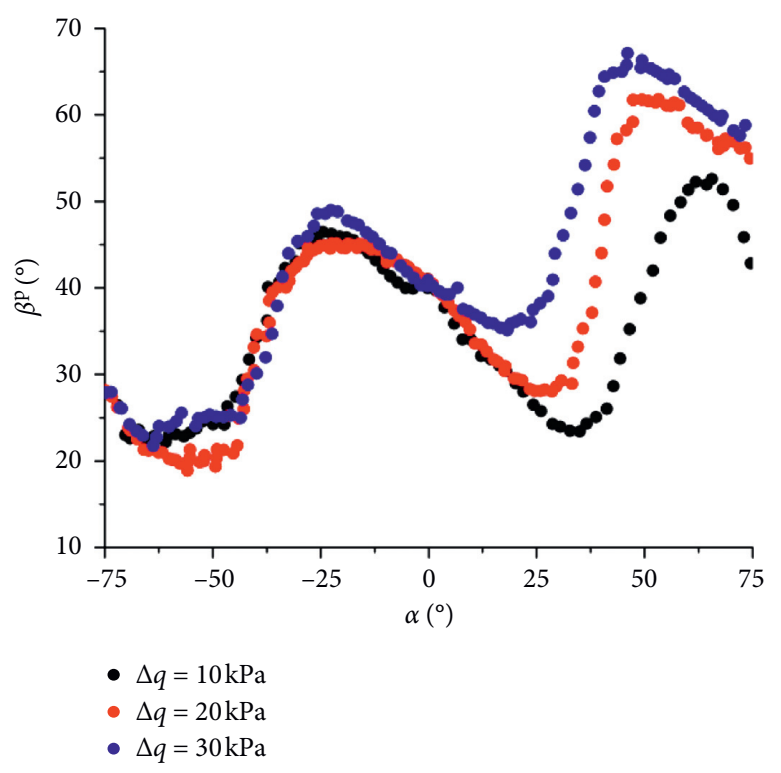

Figure 11: Dependence of $\beta^{p}$ on $\alpha$ with different deviatoric stress amplitudes $(\Delta q)$.

It is shown that $\beta^{p}$ is small in the first few cycles, and $\beta^{p}$ versus $\alpha$ plots gradually shift in the left-upward direction with increases in $N$. Hence, the trends of the $\beta^{p}$ versus $\alpha$ plots are "forward-shifted" by increases in $N$. The $\beta^{p}$ versus $\alpha$ plot stabilizes and is unchanged after the 7th cycle. Hence, the cycle number has a significant impact on the noncoaxiality angle in coupled conditions. Figure 12 also shows that the fluctuations of the noncoaxiality angle are not affected by the number of cycles.

\section{Analysis of the Mechanisms of Noncoaxiality}

The change vectors of the plastic strain increments of $\mathrm{Cq} 3$ were plotted (Figure 13) to elucidate the mechanisms responsible for noncoaxiality in remolded loess under repeated cyclic loads. The direction and length of the arrows represent the directions and magnitudes of the plastic strain increments, respectively. It may be observed that if the direction of the plastic strain increment is the same as the direction of stress increment, i.e., $\alpha_{d \varepsilon}^{p}=\alpha_{d \sigma}^{p}$, the change in plastic strain is, then, uniquely determined by the stress increment. The material is, therefore, purely elastic, and the plastic deformations of the material are due to the plastic strain rate effect [23]. When plastic strain is solely determined by the current stress state and is unrelated to the stress increment, i.e., $\beta^{p}=0$, the material exhibits coaxial plasticity.

In Figure 13, it is shown that the orientation of the plastic strain increments is generally between those of the principal stress and principal stress increments. Varying degrees of noncoaxiality are always present in the plastic strain increment vectors at each value of $\Delta q$. Furthermore, in any given cycle, the plastic strain increment induced by some stress increment is not the same throughout that cycle, as the plastic strain response to stress increments depends on the range of values taken by $\alpha$ in a "segmented" manner. For 


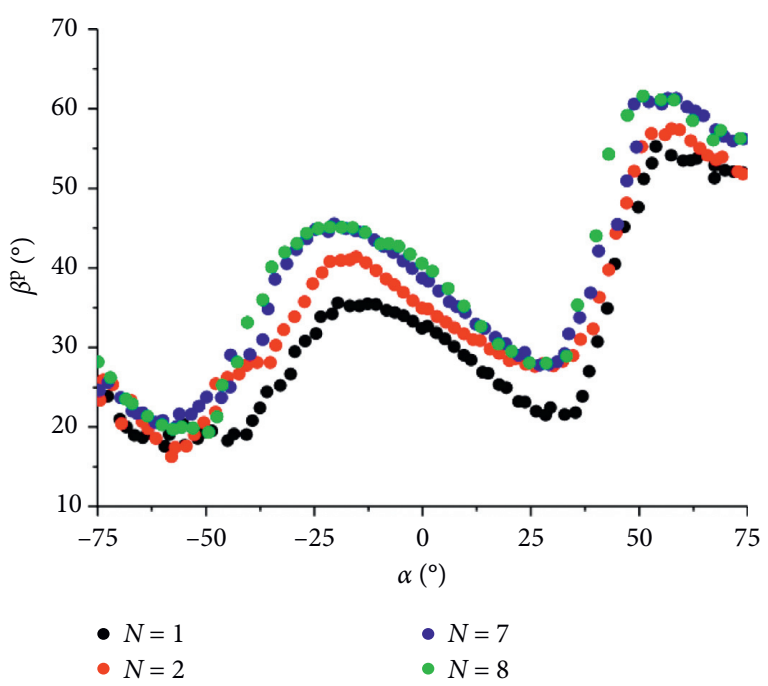

FIgURE 12: $\beta^{p}$ versus $\alpha$ versus plots with different cycle numbers.

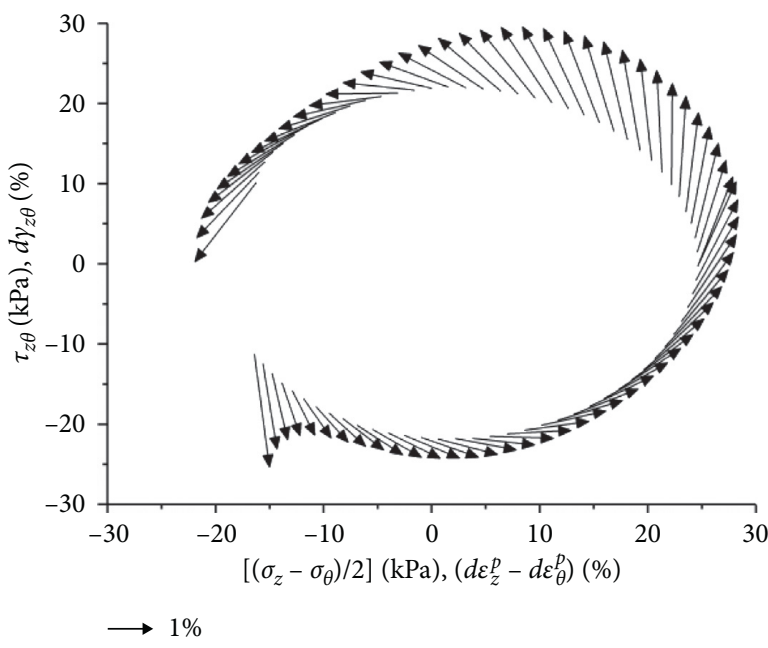

(a)

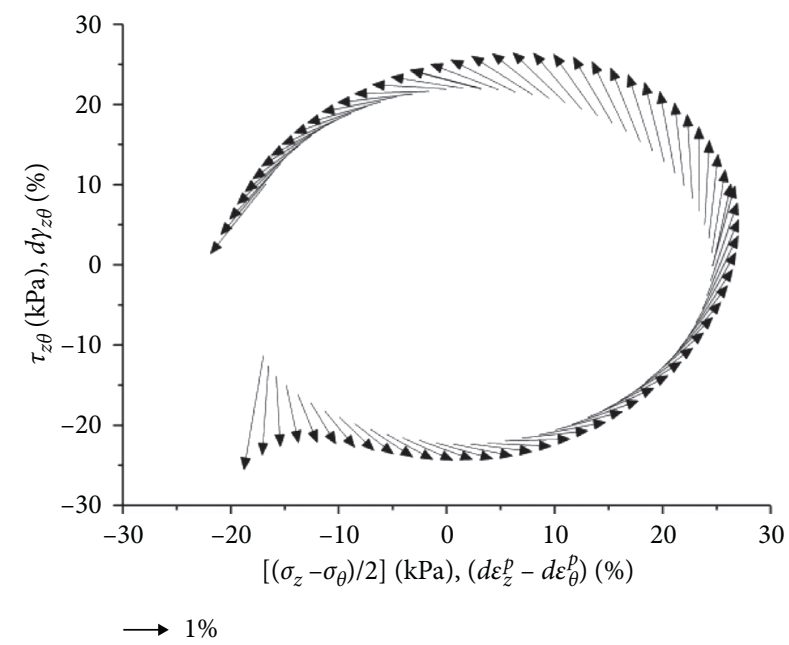

(b)

FIGURE 13: Change vectors of the plastic strain increments of Cq3: (a) 1st cycle and (b) 8th cycle.

example, when $\alpha$ varies between $\left[-45^{\circ}, 0^{\circ}\right]$ and $\left[45^{\circ}, 75^{\circ}\right]$ in the first cycle (Figure 13(a)), the absolute value of $\tau_{z \theta}$ decreases, the absolute value of $\left(\sigma_{z}-\sigma_{\theta}\right) / 2$ increases, and $\left(d \varepsilon_{1}-d \varepsilon_{3}\right)$ decreases. Within these ranges, increases in $\alpha$, therefore, increase the stiffness of the soil body and weaken its coaxial plasticity; therefore, the plastic stress rate effect is strong in these ranges of $\alpha$, which leads to large $\beta^{p}$ values. When $\alpha$ varies between $\left[-45^{\circ}, 0^{\circ}\right]$ and $\left[45^{\circ}, 75^{\circ}\right]$, increases in $\alpha$ lead to increases in the absolute value of $\tau_{z \theta}$ and decreases in the absolute value of $\left(\sigma_{z}-\sigma_{\theta}\right) / 2$, thus decreasing the soil body stiffness and strengthening coaxial plasticity. Therefore, the plastic stress rate effect is weaker in these ranges, and the value of $\beta^{p}$ is relatively small. Based on a comparison with Figure 11, it may also be observed that the "segmented" behavior of the plastic strain increments in response to $\alpha$ is identical to that of $\beta^{p}$. Furthermore, Figures 6 and 13 show that increases in the cycle number are accompanied by increases in the soil body stiffness, reductions in the coaxial plasticity in each rotational interval, more pronounced plastic stress rate effects, and increases in $\beta^{p}$. In summary, noncoaxiality is caused by anisotropies and cyclic changes in the soil body stiffness.

\section{Conclusions}

(1) Elastic strains significantly influence the noncoaxiality of remolded loess; the noncoaxiality of a soil body will be overestimated if the effects of elastic strain are overlooked. In coupled conditions, elastic strains mainly affect the minima of the noncoaxiality angle $\beta^{p}$ in remolded loess; the effects of elastic strains on the maxima of $\beta^{p}$ are relatively small.

(2) Reversals in the rotation of the principal stress axis lead to dramatic changes in the $\beta^{p}$ of remolded loess and reversals in the direction of the plastic strain increments. Hence, the direction of plastic strain 
increment is significantly affected by the direction of stress increments. The fluctuations of $\beta^{p}$ are largely identical throughout the processes of repeated PSAR.

(3) In coupled conditions, the intermediate principal stress coefficient $b$ affects the magnitude of $\beta^{p}$ in remolded loess. $\beta^{p}$ increases with increase of $b$, but the development of $\beta^{p}$ is not significantly affected by $b$. The deviatoric stress amplitude $(\Delta q)$ does not affect the fluctuations of $\beta^{p}$, but has a significant effect on the development and magnitude of $\beta^{p}$. The number of cycles also has a significant impact on $\beta^{p}$.

(4) In coupled conditions, the deformation stiffness of remolded loess is anisotropic, and it changes with increase of the cycle number. The effects of deformation stiffness on plastic strain increments and $\beta^{p}$ are identical. Hence, the noncoaxiality of remolded loess is caused by anisotropies and cyclic changes in its stiffness.

\section{Data Availability}

The data used to support the findings of this study are included within the article.

\section{Conflicts of Interest}

The authors declare that there are no conflicts of interest regarding the publication of this paper.

\section{References}

[1] K. H. Roscoe, R. H. Bassett, and E. R. L. Cole, "Principal axes observed during simple shear of a sand," in Proceedings of the 4th European Conference on Soil Mechanics and foundation Engineering, pp. 231-237, Lisbon, Portugal, 1967.

[2] Y. Cai, H.-S. Yu, D. Wanatowski, and X. Li, "Noncoaxial behavior of sand under various stress paths," Geotechnical and Geoenvironmental Engineering, vol. 139, no. 8, pp. 1509-1518, 2013.

[3] Y. Nakata, M. Hyodo, H. Murata, and N. Yasufuku, "Flow deformation of sands subjected to principal stress rotation," Soils and Foundations, vol. 38, no. 2, pp. 115-128, 1998.

[4] Y. Nakata, M. Hyodo, and H. Murata, "Non-coaxiality of sand subjected to principal stress rotation," in Proceedings of the Conference on Deformation and Progressive Failure in Geomechanics, pp. 265-270, Nagoya, Japan, 1997.

[5] M. Blanc, H. D. Benedetto, and S. Tiouajni, "Deformation characteristics of dry hostun sand with principal stress axes rotation," Soils and Foundations, vol. 51, no. 4, pp. 749-760, 2011.

[6] Q. Sun, "Experimental study on dynamic behaviour of saturated sand under complex stress paths," Doctoral dissertation, Zhejiang University, Hangzhou, China, 2015.

[7] J. S. Liu, L. G. Wang, and X. D. Zhang, "Experimental study on non-coaxial characteristics of $\mathrm{K} 0$ consolidation saturated silty clay," Chinese Journal of Rock Mechanics and Engineering, vol. 36, pp. 4205-4211, 2017.
[8] Y. H. Yang, "Experimental study on the non-coaxiality on the soft clay," Doctoral dissertation, Zhejiang University, Hangzhou, China, 2014.

[9] J. G. Qian and Z. B. Du, "Cyclic degradation and noncoaxiality of saturated soft clay subjected to pure rotation of principal stress axis," Chinese Journal of Geotechnical Engineering, vol. 38, pp. 1381-1390, 2016.

[10] W. Li, J. Q. Zhuang, and Y. W, "Experimental study on influencing factors of shear strength of saturated remolded loess," Journal of Engineering Geology, vol. 26, no. 3, pp. 626-632, 2017.

[11] L. Zhang, C. L. Chen, and D. F. Zhang, "Mechanical properties of saturated remolded loess under partial drainage conditions," Journal of Hydroelectric Engineering, vol. 38, no. 12, pp. 112-120, 2019.

[12] H. J. Yu, E. L. Liu, and R. J. Li, "Dynamic characteristics and residual deformation of saturated remolded loesses," Journal of Natural Disasters, vol. 27, no. 6, pp. 186-196, 2018.

[13] X. B. Yue, L. Y. Zhao, and Y. L. Xie, "Strain-loading rates time model of remolded saturated loess," Journal of Wuhan University of Science and Technology, vol. 34, no. 6, pp. 101104, 2012

[14] P. Hu, C. Wei, and L. Q. Yang, "Deformation behavior of sands under reciprocating cyclic principal stress rotation," Chinese Journal of Underground Space and Engineering, vol. 14, no. 4, pp. 955-961, 2018.

[15] Z. X. Yang, X. S. Li, and J. Yang, "Undrained anisotropy and rotational shear in granular soil," Géotechnique, vol. 57, no. 4, pp. 371-384, 2007.

[16] G. D. Jiao, S. P. Zhao, and W. Ma, "Evolution laws of hysteresis loops of frozen soil under cyclic loading," Chinese Journal of Geotechnical Engineering, vol. 35, no. 7, pp. 1343-1349, 2013.

[17] X. B. Yang, E. L. Liu, and X. X. Han, "Experimental study on energy evolution of sandstone under uniaxial cyclic loading," Coal Technology, vol. 37, no. 4, pp. 21-23, 2018.

[18] B. O. Hardin and G. E. Blandford, "Elasticity of particulate materials," Journal of Geotechnical Engineering, vol. 115, no. 6, pp. 788-805, 1989.

[19] J. J. Yan, J. Zhou, and Z. Y. Liu, "Elasto-plastic deformation behavior of intact clay subjected to principal stress rotation," Chinese Journal of Rock Mechanics and Engineering, vol. 33, pp. 4350-4358, 2014.

[20] D. Pradel, K. Ishihara, and M. Gutierrez, "Yielding and flow of sand under principal stress axes rotation," Soils and Foundations, vol. 30, no. 1, pp. 87-99, 1990.

[21] Z. X. Tong, J. M. Zhang, and Y. L. Yu, "Effects of intermediate principal stress parameter on deformation behavior of sands under cyclic rotation of principal stress axes," Chinese Journal of Geotechnical Engineering, vol. 31, pp. 946-952, 2009.

[22] Z. B. Du, J. G. Qian, and M. S. Huang, "Experimental study on deformation behavior of saturated soft clay under traffic loading considering effect of principal stress rotation," Chinese Journal of Rock Mechanics and Engineering, vol. 35, pp. 1031-1040, 2016.

[23] J. W. Rudnicki and J. R. Rice, "Conditions for the localization of deformation in pressure-sensitive dilatant materials," Journal of the Mechanics and Physics of Solids, vol. 23, no. 6, pp. 371-394, 1975. 